\title{
Dental Students' Tobacco Smoking Habits, Second-hand Smoke Exposure, and Training in Cessation Counselling at the University of Medicine Pharmacy Sciences and Technology of Târgu Mureș
}

\author{
Márta Germán-Salló1, Zoltan Preg ${ }^{1 \star}$, Dalma Bálint Szentendrey¹, Enikő Nemes-Nagy ${ }^{1}$, Mihály Imre \\ László1 ${ }^{1}$ Zita Fazakas ${ }^{1}$, Edith Simona lanosi ${ }^{1}$, Pál István Kikeli², Zoltán Ábrám¹, Péter Balázs ${ }^{3}$ \\ 1. University of Medicine Pharmacy Sciences and Technology of Targu Mures, Romania \\ 2. Procardia Medical Unit, Targu Mures, Romania \\ 3. Semmelweis University, Budapest, Hungary
}

\begin{abstract}
Objectives: To describe tobacco smoking habits, attitudes, second-hand smoke exposure, and training in cessation counselling at the University of Medicine Pharmacy, Sciences and Technology of Târgu-Mureș (UMPSTTM), as baseline data for the first Romanian university to implement a Smoke Free University Project. Methods: A cross-sectional survey was administered in 2014 among dental students at UMPSTTM to explore their smoking habits, attitudes toward smoking and tobacco control policies, exposure to second-hand smoke, interest in quitting, and their knowledge about cessation counselling. We used core questions of the Global Health Professions Student Survey (GHPSS) and added specific items related to the Smoke Free University Project. Data were analysed by SPSS v22 software. We compared our results with those of the GHPSS Survey. Results: 581 dental students, $73.1 \%$ of the target population ( $n=795)$, completed the questionnaire. $38.7 \%$ were current smokers. Approximately 1 in 5 (22.6\%) current smokers admitted smoking inside university buildings, although $80.7 \%$ were aware of the smoking ban. $44.2 \%$ of current smokers plan to quit smoking. Nearly half of the students (48.9\%) were exposed to secondhand smoke in their current homes, $78.1 \%$ in public places and $33.3 \%$ inside the university buildings. Only $21.0 \%$ of all participants received any formal training on how to help future patients quit. Conclusions: Tobacco use prevalence was higher among future dentists than in the majority of respondents to the GHPSS. Changes in dental school education are needed to promote personal smoking cessation, as well as to educate dentists on how to support their future patients quitting.
\end{abstract}

Keywords: smoking, dental students, smoking cessation, training

Received 19 February 2019 / Accepted 4 April 2019

\section{Introduction}

According to Geoffrey Rose: "It is better to be healthy than ill or dead. That is the beginning and the end of the only real argument for preventive medicine. It is sufficient" [1].

Tobacco use is a man-made pandemic with a huge impact on public health. Smoking is not just a bad habit it is a severe addiction affecting body and mind, leading to serious conditions, disability, and death. Smoking is an important risk factor for many oral diseases, such as mucosal and periodontal diseases or cancer [2]. There is growing evidence, that oral status reflects the general physical and mental health, and periodontitis may be indicative of other chronic diseases like atherosclerosis, stroke, myocardial infarction and diabetes [3]. The progress of numerous oral diseases is reversible, and survival rates for early diagnosed oral cancers are high, if treated in the initial stages [4].

Dentists have an important role in preventing initiation of tobacco and promoting cessation. According to the FDI World Dental Federation "oral health professionals are in a unique position to contribute to tobacco control". They have the opportunity, responsibility and obligation to change their patients' behaviour, to protect them of falling victim to the world epidemic. [5] To increase the capacity of dentists and other health professionals to curb tobacco use, UMPSTTM was the first health professional university in Romania to launch a comprehensive smoke-free initiative. The initiative includes assessment of smoking habits, attitudes toward smoking, exposure to second-hand smoke, level of knowledge related to smoking cessation methods, with the aim of promoting non-smoking among students and ensuring a smoke free environment in the medical campus.

\section{Methods \\ Design}

A cross-sectional survey of Dental Faculty students from all study years (1 to 6) was made in March 2014 as part of the Smoke Free University project. Trained data collectors distributed the questionnaires and answer sheets designed for immediate electronic scanning. From a target population of 795 students, 581 (73.1\%) completed the questionnaires. This study was approved by the Institutional Ethics Committee of UMPSTTM. 


\section{Measurement}

The 72-item questionnaire included: 42 core questions from Global Health Professions Student Survey GHPSS and 30 questions specific to our study. Questions were structured into 7 sections as follows:

Section 1: Demographics (age, gender, year of study, faculty, language of study);

Section 2: Tobacco use (experimenting cigarette smoking and/or other tobacco products, age of smoking the first time, days of smoking and/or using other tobacco products during the past month, age of starting smoking regularly, smoking and/or using other tobacco products on university campus and/or in buildings during the past year, smoking status of parents and their cardiovascular or pulmonary diseases;

Section 3: Addiction and cessation (time elapsing to light up the first cigarette after waking up in the morning, actual willingness to quit and/or change for other tobacco products, attempts to quit during the last year, getting help or advice on cessation, quitting advice to patients depending on the smoker status of the health professional);

Section 4: Environmental tobacco smoke (ETS) especially in confined spaces of the university concerning smoking ban and its enforcement);

Section 5: Attitudes toward smoking (opinion on smoking ban policy, health professional's role model and its importance in smoking cessation counselling for patients);

Section 6: Knowledge and training (level of knowledge of tobacco use and cessation techniques);

Section 7: Smoke Free University program (asking students about their intention to advice patients to quit smoking and whether they feel capable of doing that based on their current knowledge, their interest attending the tobaccology course, willingness of being involved in the Project and their opinion on the impact of the Project on smoking habits of students and teachers, and finally the students' opinion about placing specially designed smoking areas outside the university buildings, perceived smoking behaviour at UMPSTTM);

Data were analysed using IBM-SPSS v.22 software. Bivariate analyses were conducted using chi square test $(\mathrm{p}<0.05)$. Results were compared with GHPSS data of third year dental students around the world, and Global Adult Tobacco Survey GATS data collected in Romania 2011.

\section{Results}

\section{Demographic characteristics}

Respondents were 63\% females aged between 19-24 years old.

\section{Smoking behaviour}

Most of the respondents (81.6\%) reported having experimented with cigarettes (even only one or two puffs). Most of them $(76.0 \%)$ admitted smoking initiation before 18 years old, while $24.0 \%$ experienced cigarettes for the first time later at the university.

According to the current smoker definition (anyone who has smoked in the last 30 days prior to the survey), there were $61.3 \%$ non-smokers, $38.7 \%$ smokers, $9.4 \%$ daily smokers (9.01\% of females and $10.23 \%$ of males). Prevalence of smoking was nearly the same in each year. Overall prevalence of females was $38.5 \%$ that of males $39.1 \%$ with no significant gender difference $(p=0.48)$.

The age of smoking initiation was under 19 years in $66.2 \%$ and $33.8 \%$ started over 19 years.

Table I. shows the current use of other tobacco products (at least once in the past month) Prevalence decreased significantly from $18.4 \%$ of $1^{\text {st }}$ year students to $6.7 \%$ of $6^{\text {th }}$ year students. $(\mathrm{p}=0.04)$.

As a marker of nicotine dependence, 31 students (13.7\%) admitted to smoking the first cigarette within 10 minutes after waking up in the morning, 105 (46.6\%) smoked the first cigarette between 10 and 30 minutes. Among daily smokers, 30 students (54,5\%) lit up the first cigarette within the first 30 minutes after waking up in the morning.

Among all current smokers, 100 students (44.4\%) were interested in quitting smoking as soon as possible. Past attempts to quit in the previous year were reported by 102 students (45.3\%). 56.3\% thinks that they will definitely quit smoking in the following five years ("probably quits" $33.9 \%)$. Only a minority (1.8\%) anticipates continued smoking beyond five years ("probably continues" $8.1 \%$ ). Among 225 current smokers only 103 (45.7\%) received help or advice when trying to quit smoking.

Most students were aware of smoke free policy in hospitals $(80.7 \%)$ and university buildings (82.6\%). $60.2 \%$ report that this policy is enforced efficiently, while $34.3 \%$ do not; almost 1 in 10 did not realize there was a smoking ban in all educational facilities. 188 students $(2.5 \%$ of all students and $83.5 \%$ of current smokers) admitted having

Table I. Prevalence of current tobacco use by year of study and gender

\begin{tabular}{|c|c|c|c|c|c|c|c|c|}
\hline \multirow{2}{*}{$\begin{array}{l}\text { Year of } \\
\text { study }\end{array}$} & \multicolumn{4}{|c|}{ Current cigarette smokers } & \multicolumn{4}{|c|}{ Current use other tobacco products } \\
\hline & Total\% (N) & $\begin{array}{l}\text { Female\% } \\
\text { (N) }\end{array}$ & $\begin{array}{l}\text { Male\% } \\
\text { (N) }\end{array}$ & $P$ value & $\begin{array}{l}\text { Total\% } \\
\text { (N) }\end{array}$ & $\begin{array}{l}\text { Female \% } \\
\text { (N) }\end{array}$ & $\begin{array}{l}\text { Male\% } \\
\text { (N) }\end{array}$ & $P$ value \\
\hline 1 & $35(36)$ & $33.3(22)$ & $37.8(14)$ & 0.64 & $18.4(19)$ & $9(6)$ & $35.1(13)$ & 0.001 \\
\hline 3 & $39.9(55)$ & $43.2(38)$ & $34(17)$ & 0.28 & $10.9(15)$ & $8(7)$ & $16(8)$ & 0.14 \\
\hline 4 & $41.6(50)$ & $40(28)$ & $44(22)$ & 0.66 & $17.5(21)$ & $8.5(6)$ & $30(15)$ & 0.002 \\
\hline 5 & $37.5(24)$ & $32.4(12)$ & $44.4(12)$ & 0.32 & $10.9(7)$ & $10.8(4)$ & $11.1(3)$ & 0.96 \\
\hline All years & $38.7(225)$ & $38.5(141)$ & $39.1(84)$ & 0.48 & $15.5(90)$ & $10.1(37)$ & $24.6(53)$ & $<0.001$ \\
\hline
\end{tabular}


smoked on campus including $51(8.8 \%$ of all students and $22.6 \%$ of current smokers) who reported smoking inside the university buildings.

38 students $(6.6 \%$ of current students and $42.2 \%$ of current users) declared that they had used other tobacco products (e.g. chewing tobacco, snuff, bidis, cigars, hookah or pipes) on the campus and 15 students $(2.6 \%$ of all students and $16.6 \%$ of current users) admitted use inside the university buildings.

\section{Exposure to second-hand smoke SHS}

During 7 days prior to the survey, $48.9 \%$ indicated they were exposed SHS in their homes, and $16.0 \%$ admitted daily exposure. Outside their homes, $78.1 \%$ indicated any SHS exposure and $17.6 \%$ admitted daily exposure.

In the university's central building $33.3 \%$ of non-smokers were exposed to SHS I the 7 days preceding the survey. About 1 in 3 students (29.4\%) reported exposure 1-4 of the previous 7 days, while $6.6 \%$ reported exposure every day in the preceding week. In the inpatient university clinics, $31.3 \%$ of non-smokers realized SHS in confined spaces. In students' dormitories, $72.4 \%$ of the non-smokes reported second-hand smoke exposure.

\section{Attitudes toward smoking policies}

Attitudes towards legislation of tobacco control and the awareness of their future role model for patients differ significantly across non-smoker and smoker students. Table II. summarizes these attitudes related to the actual smoking status.

Students often tolerate their smoking peers even when they smoke inside the university buildings where smoking is banned. One-third (33.3\%) considered that it is not their "business" if they realize someone smoking inside the university buildings, although $37.4 \%$ criticized this behaviour. $17.4 \%$ reported that they would refer smokers to designated smoking areas, but only $10.3 \%$ affirmed they would inform smoking persons that they behave illegally.

\section{Training of dental students about tobacco cessation}

$21 \%$ of participants stated that they had received formal training in smoking cessation, although $91.9 \%$ of the stu- dents wanted to be trained in this regard. Most students indicated that they learned about the dangers of smoking (71.9\%), the importance of recording tobacco use as part of the patient's general medical history $(73.1 \%)$, and they were informed about nicotine replacement therapy options $(90.7 \%)$. The training is lacking information about reasons why people smoke $(33.4 \%)$, practical smoking cessation approaches $(21.2 \%)$, significance of providing educational materials to support cessation to patients who want to quit smoking $(23.3 \%)$, and options of pharmacotherapy to support tobacco cessation programs (27.4\%).

Based on their current knowledge, only $27.9 \%$ are convinced that they are able to deliver smoking cessation advice to smoking patients, while $55.3 \%$ feel that they were probably able to support the patients Most students (63.4\%) declared that they would be interested attending special tobacco course about the risks of smoking, benefits of cessation, cessation techniques, and basics of nicotine replacement therapy.

\section{Discussion}

Overall prevalence of current smoking in Romania (a middle income country) was $26.7 \%$, being more than two times higher among men (34.9\%) than women (14.5\%). An inquiry upon the prevalence of smoking among medical doctors $(n=1,136)$ in Romania revealed the overall prevalence of $43.2 \%$ ( $50.1 \%$ of males and $38.6 \%$ of females) [7]. It is far from $2025 \mathrm{WHO}$ suggestion of $15.0-19.9 \%$. According to Professor Richmond: "Leadership from the medical profession is essential if the world is to reduce preventable diseases caused by smoking" [8].

Our results provide evidence based data about smoking habits and attitudes of dental students at UMPSTTM. Their smoking prevalence of $38.7 \%$ was considerably higher compared to Romanian adult overall population $(22.6 \%$ in age group 15-24 years), and especially high among female students $(38.5 \%)$ contrasted to $16.7 \%$ of Romania's adult female population [6]. However, our study showed no significant gender difference of cigarette smoking.

The Global Youth Tobacco Survey (2009) indicates that $13.5 \%$ of Romanian school students aged 13-15 years have smoked at least one cigarette in the past 30 days. The

Table II. Dental students' attitudes toward tobacco control and quit smoking support, stratified by their smoking status

\begin{tabular}{|c|c|c|c|c|}
\hline \multirow{2}{*}{$\begin{array}{l}\mathrm{N}=581 \\
\text { Variables }\end{array}$} & \multicolumn{4}{|c|}{ Percentage "of yes" answers to the questions } \\
\hline & Overall \% & Non- smokers \% & Smokers \% & p value \\
\hline Should tobacco sales to adolescents be banned? & 92.9 & 96.0 & 87.9 & $<0.0001$ \\
\hline Should advertising be completely banned? & 77.5 & 83.1 & 68.4 & $<0.0001$ \\
\hline Do you agree with smoking ban in restaurants? & 82.6 & 92.1 & 67.4 & $<0.0001$ \\
\hline Do you agree with smoking ban in discos/bars/pubs? & 58.2 & 73.0 & 34.7 & $<0.0001$ \\
\hline Do you think that smoking in all public spaces should be banned? & 73.9 & 85.4 & 55.8 & $<0.0001$ \\
\hline Should health professionals get cessation training? & 91.9 & 95.7 & 86.6 & $<0.0001$ \\
\hline Are health professionals role models? & 71.8 & 73.8 & 68.8 & 0.11 \\
\hline Should health professionals give quitting advice routinely? & 90.4 & 94.4 & 84.0 & $<0.0001$ \\
\hline Should health professionals advise stopping other tobacco products? & 86.4 & 88.3 & 81.8 & 0.007 \\
\hline Do health professionals have a role in giving advice? & 91.7 & 92.1 & 91.1 & 0.38 \\
\hline Do chances of quitting improve if health professional gives advice? & 78.4 & 81.7 & 73.2 & 0.01 \\
\hline Are health professionals who smoke less likely to advise patients to stop smoking? & 44.5 & 47.5 & 39.9 & 0.08 \\
\hline
\end{tabular}


European School Survey Project on Alcohol and Other Drugs (2011) Report shows that among 15- to 16-yearold Romanian students $29 \%$ smoked in the last 30 days. Another study from 2016 reported $24.1 \%$ prevalence of smoking in the last 30 days among 15 years old adolescents living in Târgu Mureș [9], this prevalence increases among 19-24 years old dental students according to our study to $38.7 \%$. These numbers mean that between 13 and 24 years adolescents are at an increased risk of becoming smokers.

Comparing our results with GHPSS dental data of European countries (Table III.) female rates are similarly high and Romania was on the $4^{\text {th }}$ place of the negative list of 16 countries. Although, overall prevalence rate of smoking was high, daily smoking was less frequent among dental students compared to the 15-24 age group of Romania's general population. Previous surveys in Romania about smoking habits of dental students found similarly high smoking rates $[10,11]$. This might have been due to the lack of tobacco-control programs of professional education. Lacking of relevant programs even now explains why there was no difference by academic years of smoking rates in our survey.

Current use of other tobacco products was higher among male students as was in all European countries from the GHPSS study [12].

Many students started smoking before entering university, which is consistent with GATS findings with highest proportion of initiation at age 17-19 [6].

"Health workers should look at themselves before trying to convince others to quit smoking" [9]. Results of our survey showed not only a widespread use of tobacco among dental students, but also lack of willingness to quit smoking in more than half of current smokers. It is a considerably high proportion if compared with $33.6 \%$ of current smokers interested in quitting in the general population of Romania [6]. This can also be related to the fact that less than half of current smokers among dental students

Table III. Prevalence of cigarette smoking in selected European countries according to Dental Global Health Professions Student Survey compared with UMPSTTM data of 3rd year dental students.[12]

\begin{tabular}{lcccc}
\hline Country & year & Total\% & Male\% & Female\% \\
\hline Republic of Moldova & 2008 & 65.2 & 69.1 & - \\
Macedonia & 2009 & 52.5 & 52.4 & 52.5 \\
Bulgaria & 2009 & 52.2 & 49.3 & 54.7 \\
Kyrgyzstan & 2008 & 44.0 & 60.9 & 27.8 \\
Russian Federation & 2006 & 43.7 & 53.3 & 37.9 \\
Greece & 2009 & 39.1 & 31.7 & 43.5 \\
Romania (UMPSTTM) & 2014 & 38.7 & 38.5 & 39.1 \\
Bosnia Herzegovina & 2006 & 36.1 & 34.1 & 37.1 \\
Czech Republic & 2006 & 33.3 & 29.4 & 34.4 \\
Albania & 2005 & 30.1 & 38 & 27 \\
Lithuania & 2006 & 29.6 & 61.7 & 22.9 \\
Slovakia & 2006 & 29.3 & 23.1 & 32.1 \\
Serbia & 2006 & 28.5 & 24.7 & 31 \\
Armenia & 2006 & 28.4 & 60.2 & 7.8 \\
Latvia & 2009 & 19.6 & 32.4 & 32.1 \\
Slovenia & 2007 & 17.9 & - & 17.6 \\
\hline
\end{tabular}

received any help or advice on smoking cessation. Only a small percentage of participants think they will be smokers after 5 years, however they are identical with the nicotine dependent subsample.

\section{Second-hand smoke exposure}

In Romania, despite of implementing smoking ban in indoor areas of public places including hospitals and educational facilities exposure did not change to ETS [13].

Our results of SHS exposure resemble those of GHPSS study in high rate European countries (32 of 48) [12]. More than 2/3 (78.1\%) of UMPSTTM dental students reported SHS exposure outside their homes during the week prior to data collection. (comparing Republic of Moldova 79.2\%, Kyrgyzstan 78.2\% Slovakia 71.4\%, Slovenia $74.4 \%$ ) [12].

One third of non-smoker dental students (33.3\%) reported exposure to SHS in university buildings however $47.5 \%$ of the general population realized tobacco smoke in universities of Romania [6]. We found higher prevalence of reported indoor SHS exposure in our dental students' homes contrasted to the Romanian adult population (48.9 $\%$ versus $35.4 \%$ of GATS) [6]. Indoor exposure is mounting $(72.0 \%)$ if related to the dental students' dormitoriesDespite the fact that dental students were mostly aware of non-smoking policy rules, they disrespected them while admitting that they did not realize any control. Attitudes of dental students toward smoking regulation policies and health professional's role in tobacco cessation counselling depended heavily on their smoking status. Smokers were less likely to support smoking control policy, like smoking ban in all confined public spaces, restaurants, discos/ bars/pubs, and they did also not support complete ban on advertising tobacco products and tobacco sales to underage people. Smoking status also proved to decrease the willingness to be trained in smoking cessation counselling and to provide patients advice to quit. Both smokers and nonsmokers agreed on health professional's role model. Comparing the share of relevant opinion of our dental students (91.7\%) with those of other European countries, 8 countries out of 10 placed behind UMPSTTM with highest value in Latvia (90.5\% and the lowest in Slovakia 56,8\%). Findings were the same regarding the opinion of providing health professionals with specific training on cessation techniques (UMPSTTM 91.9\%, Latvia 90.0\% and Macedonia 78.0\%). Results of our study and those of GHPSS indicate that dental schools failed to meet this demand. Except Moldova (63.1\%) among other European countries, less than half of dental students have ever received any formal training in smoking cessation counselling. The lowest value shows Slovakia (14.0\%) and UMPSTTM was in the lower third $(21.0 \%)$ of the range [12].

"Dental practice in the 21 st century will increasingly move from a restorative orientation to one of broader promotion of health and well-being. It is unconscionable to not include aggressive tobacco intervention in that new 
paradigm." [14] Discouraging tobacco use among dental students, offering them a smoke free environment and including education about tobacco in their medical curricula may help to translate ideas into action. We hope that the Smoke Free University project is a good start and will help in developing efficient tobacco control program at all Romanian universities.

\section{Limitations and strengths of the study}

Our data were based on anonymous voluntary answered questionnaires, this fact constitutes the strength and in same time the limitation of the study. Results of this study provided reliable baseline data of dental students' smoking behaviour, attitudes, cessation plans, and their knowledge about smoking cessation counselling.

\section{Conclusions}

Tobacco use prevalence is higher among future dentists compared to Romania's general population and to most of the countries taking part in the GHPSS study. Our students' attitude is ambiguous, as they disregard already implemented antismoking regulations, their willingness to quit is alarmingly low, but most of them are aware of the role model of health professionals and consider that they should receive academic education about smoking cessation interventions. Behavioural changes of dental students toward tobacco smoking are urgently needed by introducing trainings about smoking cessation counselling in the academic curricula.

\section{Authors' contribution}

Márta Germán-Salló, PhD (Conceptualization; Investigation; Methodology; Project administration)

Zoltan Preg, PhD (Conceptualization; Data curation; Formal analysis; Investigation; Methodology; Project administration; Resources; Software; Writing - original draft; Writing - review \& editing)

Dalma Bálint Szentendrey, PhD (Conceptualization; Data curation; Investigation; Validation; Visualization)

Enikő Nemes-Nagy, PhD (Conceptualization; Data curation; Formal analysis; Investigation; Methodology; Resources; Supervision; Validation)

Mihály Imre László, Dr. (Data curation; Formal analysis; Investigation; Methodology; Software; Validation; Visualization)

Zita Fazakas, PhD (Conceptualization; Investigation; Methodology; Supervision; Validation)

Edith Simona Ianosi, PhD (Conceptualization; Data curation; Investigation; Methodology; Validation)
Pál István Kikeli, PhD (Conceptualization; Data curation; Formal analysis; Funding acquisition; Investigation; Methodology; Project administration; Supervision)

Zoltán Ábrám, PhD (Conceptualization; Funding acquisition; Investigation; Methodology; Project administration; Resources; Writing - review \& editing)

Péter Balázs (Conceptualization; Formal analysis; Funding acquisition; Investigation; Methodology; Project administration; Writing - review \& editing)

\section{Aknowledgement and funding}

Research reported in this publication was supported by the Fogarty International Center and the National Cancer Institute of the National Institutes of Health under Award Number R01TW009280. The content is solely the responsibility of the authors and does not necessarily represent the official views of the National Institutes of Health.

\section{Conflict of interests}

None to declare.

\section{References}

1. Jenkins CD. Building better health: a handbook of behavioral change. Washington, D.C: Pan American Health Organization, Pan American Sanitary Bureau, Regional Office of the World Health Organization; 2003.

2. Petersen PE. Tobacco and Oral Health - the Role of the World Health Organization. Oral Health. 2003;1(4):8.

3. Li X, Kolltveit KM, Tronstad L, Olsen I. Systemic Diseases Caused by Oral Infection. Clin Microbiol Rev. 2000;13(4):547-58.

4. Tobacco and Oral Health [Internet]. Action on Smoking and Health. 2016 [cited 2019 Feb 19]. Available from: http://ash.org.uk/information-andresources/reports-submissions/reports/tobacco-and-oral-health/

5. Beaglehole $\mathrm{RH}$, Benzian HM, World Health Organization, International Dental Federation. Tobacco or oral health: an advocacy guide for oral health professionals. Lowestoft, U.K.: FDI, World Dental Press; 2005.

6. Irimie S. Global adult tobacco survey: România 2011. Cluj-Napoca: Eikon; 2012.

7. Didilescu C, Munteanu I. [The prevalence of smoking in physicians in Romania]. Pneumologia. 2000;49(2):91-4.

8. Richmond R. Teaching medical students about tobacco. Thorax. 1999 Jan 1;54(1):70-8.

9. Nădășan V, Foley KL, Pénzes M, Paulik E, Mihăicuță Ș, Ábrám Z, et al. Use of electronic cigarettes and alternative tobacco products among Romanian adolescents. Int J Public Health. 2016;61(2):199-207.

10. Didilescu A. Smoking Habits and Social Nicotine Dependence among Dental Students in Romania. 2014;13(1):6.

11. Benedek (Bukhari) C, Kerekes-Máthé B, Bors A, Kovács M, Zita F, Székely M. Smoking Related Habits and Attitudes of Dental Students. Acta Medica Marisiensis. 2012;58(5):266-71.

12. Warren CW, Sinha DN, Lee J, Lea V, Jones N, Asma S. Tobacco use, exposure to secondhand smoke, and cessation counseling training of dental students around the world. J Dent Educ. 2011;75(3):385-405.

13. LEGE nr.349 din 6 iunie 2002 pentru prevenirea și combaterea efectelor consumului produselor din tutun [Internet]. [cited 2019 Feb 19]. Available from: http://www.cdep.ro/pls/legis/legis_pck.htp_act_text?idt=36163

14. Tomar SL. Dentistry's role in tobacco control. J Am Dent Assoc 1939. 2001;132 Suppl:30S-35S. 